\title{
Comparison of three behavior modification techniques for management of anxious children aged 4-8 years
}

\author{
Sreeraksha Radhakrishna, Ila Srinivasan, Jyothsna V Setty, Murali Krishna D R, Anjana Melwani, \\ Kuthpady Manasa Hegde \\ Department of Pediatric and Preventive Dentistry, M.R. Ambedkar Dental College and Hospital, Bengaluru, Karnataka, India
}

\begin{abstract}
Background: An inability to cope with threatening dental stimuli, i.e., sight, sound, and sensation of airotor, manifests as anxiety and behavioral management problems. Behavior modification techniques involving pre-exposure to dental equipment will give children a first-hand experience of their use, sounds, and clinical effects. The aim of this study was to compare the techniques of Tell-Show-Play-doh, a smartphone dentist game, and a conventional Tell-Show-Do method in the behavior modification of anxious children in the dental operatory.

Methods: Sixty children in the age group of 4-8 years, with Frankl's behavior rating score of 2 or 3, requiring Class I and II cavity restorations were divided into three groups. The groups were Group 1: Tell-Show-Play-doh; Group 2: smartphone dentist game; and Group 3: Tell-Show-Do technique and each group comprised of 20 children. Pulse rate, Facial Image Scale (FIS), Frankl's behavior rating scale, and FLACC (Face, Leg, Activity, Cry, Consolability) behavior scales were used to quantify anxious behavior. Operator compliance was recorded through a validated questionnaire.

Results: The results showed lower mean pulse rates, lower FIS and FLACC scores, higher percentage of children with Frankl's behavior rating score of 4, and better operator compliance in both the Tell-Show-Play-doh and smartphone dentist game groups than in the conventional Tell-Show-Do group.

Conclusion: The Tell-Show-Play-doh and smartphone dentist game techniques are effective tools to reduce dental anxiety in pediatric patients.
\end{abstract}

Keywords: Anxiety; Behavior Modification; Game; Pediatric Dentistry; Smartphone.

This is an Open Access article distributed under the terms of the Creative Commons Attribution Non-Commercial License (http://creativecommons.org/licenses/by-nc/4.0/) which permits unrestricted non-commercial use, distribution, and reproduction in any medium, provided the original work is properly cited.

\section{INTRODUCTION}

The first dental experience is important in molding a child's attitude towards dentistry and dental outcomes. Cooperation of a child during dental treatment is vital to render successful and high quality treatment.

Effective communication is important and is a big challenge in the dental office. A child's cognitive develop- ment will dictate the level and amount of information exchange that can take place. Not all children are able to express their fears and anxieties and have relatively limited communication skills at younger ages. It is difficult for a 5 to 7 -year-old child to perceive an idea, for which he/she has no conceptual framework and to understand the dentist's frame of reference [1].

Child dental anxiety has been a matter of concern for many years and can be defined as a nonspecific feeling

Received: December 14, 2018 - Revised: January 18, $2019 \cdot$ Accepted: January 30, 2019

Corresponding Author: Sreeraksha Radhakrishna, Post Graduate Student, Department of Pediatric and Preventive Dentistry, M.R. Ambedkar Dental College and Hospital, Bengaluru, Karnataka, India-560005

Tel: +91-9632522065 E-mail: sreerak9@gmail.com

Copyright(c) 2019 Journal of Dental Anesthesia and Pain Medicine 
of apprehension, worry, uneasiness or dread, the source of which may be vague or unknown [2]. The sight, sound, and sensation of the airotor is rated as one of the most fear-eliciting stimuli [1]. This inability to cope with threatening dental stimuli often manifests as behavior management problems [1].

Behavior management techniques are a set of procedures aimed at enhancing a child's useful coping skills, in order to achieve complete willingness and acceptance of dental care, and ultimately reduce the child's perception that the dental situation is overwhelming or dangerous [3].

The Tell-Show-Do technique is based on the principles of learning theory and is performed by dentists themselves in the operatory [4,5]. Playing with a dental imitation toy and using euphemisms instead of demonstrating on a model or observing one, provides a better explanatory concept of the dental procedure.

With this idea, the Tell-Show-Do technique was modified into the Tell-Show-Play-doh technique, using the concept of learning by doing, in reducing children's fear and anxiety toward dental treatment and promoting adaptive behavior as shown in Fig. 1. Play-doh is a reusable, flour-based modelling compound used by children for arts and crafts projects. The Play-Doh Doctor Drill 'n Fill toy set consists of a plastic human head with slots into which Play-doh molded teeth can be inserted. A battery-operated toy drill is used to drill into and clean the black, cavitated tooth model and filled with white Play-Doh compound to simulate cavity preparation using airotor and restoration using tooth colored cement.

Smartphone dentist games that are available online, approved by a panel of experienced pedodontists for clinical usage and demonstrating the use of common dental equipment like airotor, ultrasonic scalers, suction tip, etc. in the form of animated pictures with visual and sound effects were used to give the child a first-hand experience of their usage, sounds produced, and clinical effects obtained as shown in Fig. 1.

Thus, the present study was designed to compare the effectiveness of Tell-Show-Play-doh, smartphone dentist game and conventional Tell-Show-Do techniques in reducing dental anxiety among 4 to 8 -year-old children.

\section{MATERIALS AND METHODS}

This randomized, interventional, clinical study was conducted in the Department of Pediatric and Preventive Dentistry, M.R Ambedkar Dental College and Hospital after obtaining approval from the Institutional Review Board and Ethics Committee (IRB Number: EC-536) and written informed consent from the parents and assent from the children, along with a video recording of the same. The study included 60 children, aged 4 to 8 years, with equal distribution in both genders.

Inclusion criteria:

1. Children with Frankl's behavior rating score of 2 or 3 and no prior dental experience

2. Class I or Class II carious lesion on the primary molars, limited to enamel and $2 / 3^{\text {rd }}$ of dentin and requiring a restoration without local anesthesia

Exclusion criteria:

1. Children with Frankl's behavior rating score of 1 or 4

2. Extensively damaged teeth

3. Teeth with lesions involving pulp or extending below gingiva

4. Carious teeth with pre-shedding mobility

5. Medically and developmentally compromising conditions

6. Patients with mental / cognitive problems

Using simple random sampling technique (drawing of lots), selected children were equally distributed into three groups of 20 each, group 1: Tell-Show-Play-doh, group 2: smartphone dentist game and group 3: Tell-Show-Do technique. Samples in each group were treated in a single appointment after using either of the behavior modification techniques. Class I or Class II cavities were prepared on carious primary molar and restored using Glass ionomer cement. The behavior modification tools used in the study are shown in Fig. 1. 


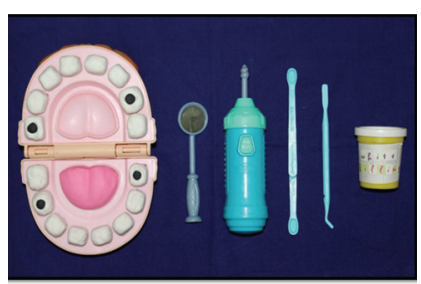

Group 1

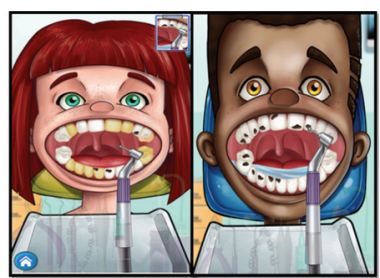

Group 2
Fig. 1. Play-Doh doctor drill ' $n$ fill toy set (Group 1) and the smartphone dentist game (Group 2)

All children were treated by a single operator in order to avoid bias.

The behavior of the child patient before and after the procedure was assessed using Frankl's behavior rating scale [6]. The level of dental anxiety of each patient was assessed using a finger pulse oximeter (model number: 6500; Nidek Medical India Pvt. Ltd.) and Facial Image Scale (FIS) [7] at four intervals of the procedure, which were:

a) Stage 1: Before the treatment procedure (in waiting/ reception area)

b) Stage 2: After using the behavior modification technique, pre-operatively

c) Stage 3: During treatment (while using airotor)

d) Stage 4: After treatment (completion of treatment)

The patient was asked to select the image from the FIS that he/she can closely associate with at that moment and the patient's pulse rate was noted. The operator graded the child's behavior during the procedure using the FLACC (Face, Leg, Activity, Cry, Consolability) behavioral pain assessment scale [8]. The ease of handling the patient (pre-operatively and during the procedure) and the ease of carrying out the procedure by the pediatric dentist after using the three behavior modification techniques was assessed using a validated questionnaire on a 5-point Likert scale ( $1=$ Very good, $2=$ Good, $3=$ Average, $4=$ Not bad, $5=$ Bad).

The data collected was tabulated and subjected to the following statistical analyses performed using SPSS statistical software package Version 22.0. A one-way ANOVA followed by Tukey's HSD post-hoc analysis was used to compare the mean FIS scores and pulse oximeter

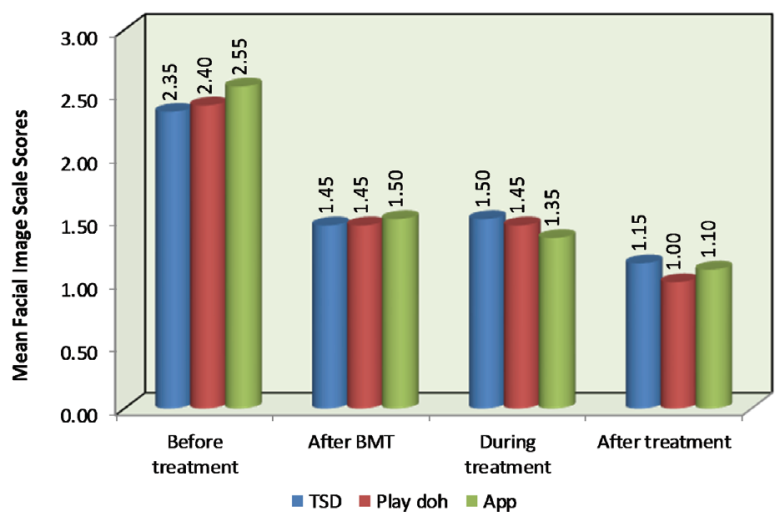

Fig. 2. Comparison of mean Facial Image Scale (FIS) scores between three study groups at different time intervals

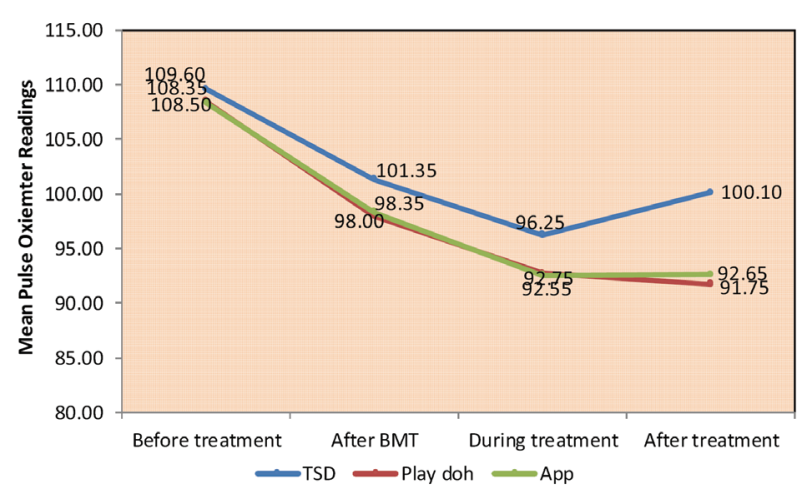

Fig. 3. Comparison of mean pulse oximeter readings between different time intervals in each study group

readings between the three study groups at different time intervals. A repeated measures ANOVA followed by Bonferroni's post-hoc analysis was used to compare the mean FIS scores and pulse oximeter readings between different time intervals in each study group. The chisquare test was used to compare the distributions of the FLACC scale scores, Frankl's scale scores, ease of handling patients, and ease of carrying out the procedure at different time intervals between the three study groups. The level of significance (P-value) was set at $\mathrm{P}<0.05$.

\section{RESULTS}

A statistically significant difference between the mean FIS scores was obtained at Stages 2 and 4 of the dental procedure in Group $1(\mathrm{P}=0.005)$ and Group $2(\mathrm{P}=0.01)$, 


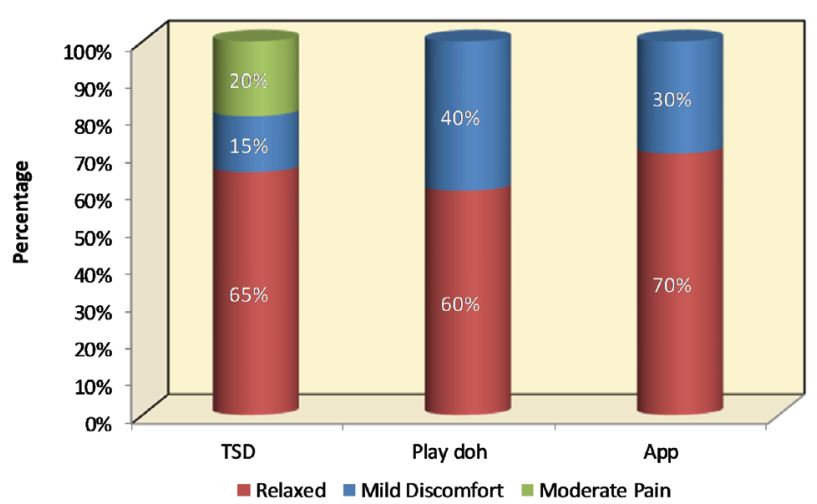

Fig. 4. Comparison of distributions of Faces Leg Activity Cry Consolabilty (FLACC) scale scores between three study groups

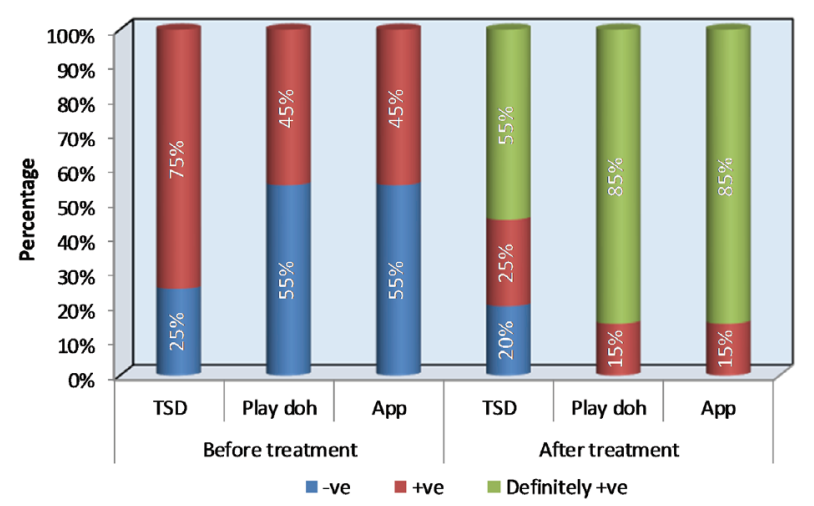

Fig. 5. Comparison of distributions of responses on Frankl's behavior rating scale at different time intervals between three study groups

Table 1. Comparison of distributions of responses for pediatric dentist questionnaire at different time intervals between three study groups

\begin{tabular}{|c|c|c|c|c|c|c|c|c|c|}
\hline \multirow{2}{*}{ Variables } & \multirow{2}{*}{ Scores } & \multicolumn{2}{|c|}{ Tell Show Do } & \multicolumn{2}{|c|}{ Play doh } & \multicolumn{2}{|c|}{ App } & \multirow{2}{*}{$\chi^{2}$ Value } & \multirow{2}{*}{ P-Value } \\
\hline & & $\mathrm{n}$ & $\%$ & $\mathrm{n}$ & $\%$ & $\mathrm{n}$ & $\%$ & & \\
\hline \multirow{5}{*}{$\begin{array}{l}\text { Ease of handling patient during } \\
\text { treatment }\end{array}$} & Bad & 0 & $0 \%$ & 0 & $0 \%$ & 0 & $0 \%$ & \multirow{5}{*}{15.675} & \multirow{5}{*}{$0.02^{*}$} \\
\hline & Not bad & 4 & $20 \%$ & 0 & $0 \%$ & 0 & $0 \%$ & & \\
\hline & Average & 1 & $5 \%$ & 0 & $0 \%$ & 0 & $0 \%$ & & \\
\hline & Good & 11 & $55 \%$ & 7 & $35 \%$ & 9 & $45 \%$ & & \\
\hline & Very good & 4 & $20 \%$ & 13 & $65 \%$ & 11 & $55 \%$ & & \\
\hline \multirow{5}{*}{ Ease of carrying out treatment } & Bad & 0 & $0 \%$ & 0 & $0 \%$ & 0 & $0 \%$ & \multirow{5}{*}{17.120} & \multirow{5}{*}{$0.009 *$} \\
\hline & Not bad & 4 & $20 \%$ & 0 & $0 \%$ & 0 & $0 \%$ & & \\
\hline & Average & 1 & $5 \%$ & 0 & $0 \%$ & 0 & $0 \%$ & & \\
\hline & Good & 11 & $55 \%$ & 6 & $30 \%$ & 8 & $40 \%$ & & \\
\hline & Very good & 4 & $20 \%$ & 14 & $70 \%$ & 12 & $60 \%$ & & \\
\hline
\end{tabular}

* Statistically Significant

indicating a greater reduction of dental anxiety in these two groups when compared to Group 3. A statistically significant difference was obtained between Stages 3 and 4 of the dental procedure in the Tell-Show-Play-doh group $(P=0.005)$, indicating the greatest reduction in dental anxiety amongst all the groups as shown in Fig. 2.

There was a significant reduction in mean pulse rate, after treatment, for both Group $1(\mathrm{P}=0.002)$ and Group $2(\mathrm{P}=0.007)$ indicating low anxiety levels in these two groups when compared to Group 3. A statistically significant difference was obtained between Stages 2 and 4 of the dental procedure in Group $1(\mathrm{P}<0.001)$ and Group $2(\mathrm{P}<0.001)$, indicating a better reduction of dental anxiety in these two groups when compared to Group 3. A statistically significant difference was obtained between Stages 3 and 4 of the dental procedure in the Tell-Show-Play-doh group $(\mathrm{P}=0.04)$, indicating the greatest reduction in dental anxiety amongst all the groups as shown in Fig. 3.

The FLACC scores showed that more patients were relaxed in the smartphone dentist game and the Tell-Show-Play-doh groups as compared to the TellShow-Do group that was statistically significant $(\mathrm{P}=$ 0.03), as shown in Fig. 4.

The Frankl's scale scores after the dental procedure showed that a greater percentage $(85 \%)$ of patients exhibited definitely positive behavior (Frankl's behavior rating 4) in Groups 1 and 2 when compared to Group 3 (55\%). More patients in the Tell-Show-Play-doh and smartphone dentist game groups exhibited definitely positive behavior, whereas there were more patients (20\%) exhibiting negative behavior (Frankl's behavior rating 2$)$ in the Tell-Show-Do group $(\mathrm{P}=0.04)$, which was statistically significant as shown in Fig. 5. 
It was appreciably easier to handle the patient during treatment and carry out the dental procedure in the Tell-Show-Play-doh and smartphone dentist game groups when compared to Tell-Show-Do group with $\mathrm{P}=0.02$ and $\mathrm{P}=0.009$ respectively, which was statistically significant as shown in Table 1.

\section{DISCUSSION}

The management of children's behavior is an integral component of pediatric dental practice. Behavior modification techniques are employed by dental practitioners to establish communication, alleviate fear and anxiety, facilitate delivery of quality dental care, build a trusting relationship between dentist, child, and parent, and promote the child's positive attitude towards oral healthcare, thus helping them to cope and show willingness to undertake dental treatment procedures [3].

The dentist must have a basic understanding of the cognitive development of the child. Based on Piaget's classification, children aged 4-7 years are in the preoperational phase. The development in vocabulary, attention, and concentration abilities in this period is a sign of their readiness for social communication. Hence, this age group is ideal for testing behavior modification techniques [1] and the positive impact that it can bring about in children.

Pulse rate is a direct measure of physiological arousal and its increase is attributed to stress during dental procedures. In the first dental visit of children, the most likely responses to dental stimuli reported would be either fear or anxiety. Thus, measuring pulse rate using a finger pulse oximeter is an objective measure for anxiety levels in children. In the present study, there was a reduction in mean pulse rate, after treatment, for both the Tell-Show-Play-doh and smartphone dentist game groups indicating low anxiety levels in these groups when compared to the Tell-Show-Do group.

The FIS is repeatable, easy to use, quick, reliable and valid. It has been used to quantify anxiety in children in various studies $[9,10]$. In the present study, the mean FIS scores were lower in both the Tell-Show-Play-doh and smartphone dentist game groups indicating low anxiety levels in these groups when compared to the Tell-Show-Do group.

The FLACC scale is a measurement used to assess pain and behavior in children between the ages of 2 months and 7 years or in individuals who are unable to communicate their pain. Recent studies have also used the FLACC scale to rate behavior in children during dental treatment [11-14]. In the present study, a majority of children in the Tell-Show-Play-doh and smartphone dentist game groups were relaxed indicating better behavior during cavity preparation and restoration, whereas a majority of children showed moderate pain in the Tell-Show-Do group.

The Frankl behavior rating scale is commonly used by researchers to study the child's behavior toward different variables $[15,16]$. In the present study, $85 \%$ of children in the Tell-Show-Play-doh and smartphone dentist game groups exhibited definitely positive behavior after dental treatment when compared with the Tell-Show-Do group $(55 \%)$

In this study it was found that it was notably easier to carry out the procedure using the Tell-Show-Play-doh and smartphone dentist game techniques than the Tell-Show-Do technique. Effective handling of patients pre-operatively and during the procedure was observed in the Tell-Show-Play-doh and smartphone dentist game techniques when compared with the Tell-Show-Do technique. The two aforementioned parameters (ease of carrying out the procedure and ease of handling patients) were previously not found to be noted in literature and therefore, were included in the present study.

This study showed a lower significance of gender on behavioral changes, which is in accordance with previous studies [17-20].

The Tell-Show-Do technique remains the most commonly used technique in pediatric dentistry and is still considered the technique with which dentists and parents are comfortable and justifies being the method of choice 
as the backbone of child education and behavior guidance during the first dental visit [1,21-23].

The modification of the Tell-Show-Do to Tell-ShowPlay-doh technique is considerably effective in reducing the pulse rate and improving behavior than the conventional Tell-Show-Do technique. The children were introduced to a Play-doh dental model and allowed to play with a battery-operated toy drill. They were shown how the suction, airotor, and air-water syringe felt and worked in a playful way. This served to familiarize them with the dental setup, helped reduce anxiety, built a bridge for future communication, and helped them prepare for further treatment sessions.

Smartphone dentist games educating child patients about the use of common dental equipment like the airotor, ultrasonic scalers, suction tip, etc. will help reduce dental fear or apprehension and give children a first-hand experience of their usage, sounds produced, and clinical effects obtained.

This study was designed to compare the efficiency of the Tell-Show-Play-doh, smartphone dentist game, and the Tell-Show-Do techniques in reducing child anxiety during dental treatment. The results of this study showed that the Tell-Show-Play-doh and smartphone dentist game techniques were more effective than the Tell-Show-Do technique on child anxiety levels and increased cooperative behavior during dental treatment among 48-year-old children, which is consistent with previous studies $[1,2,16,24,25]$.

The advantages of using the Play-Doh dental toy and smartphone dentist game are that they are convenient to use, easily available, child-friendly, playful, and require no additional virtual reality headgears.

In conclusion, it is the responsibility of pedodontists to make dentistry as child-friendly and pain-free as possible to bring about positive changes in the behavior of children during dental treatment.

The Play-Doh Doctor Drill 'n Fill toy set and "Dentist games for kids" smartphone game simulate various dental procedures to the child patient and are far superior than the Tell-Show-Do technique in reducing anxiety and in managing the child effectively during dental treatment. They are novel, simple, and effective tools that can result in improved outcomes related to dental fear and anxiety.

\section{AUHOR ORCMIDS}

Sreeraksha Radhakrishna:

https://orcid.org/0000-0002-2385-408X

Ila Srinivasan: https://orcid.org/0000-0001-9584-6954

Jyothsna V Setty: https://orcid.org/0000-0001-7346-7849

Murali Krishna D R: https://orcid.org/0000-0002-8189-6667

Anjana Melwani: https://orcid.org/0000-0001-5457-9095

Kuthpady Manasa Hegde: https://orcid.org/0000-0001-7801-1760

ACKNOWLEDGEMENTS: The authors would like to thank and acknowledge Dr. Santhosh for helping us with statistical analyses.

DECLARATION OF INTERESTS: The authors declare no financial or competing interests.

FUNDING: The authors declare no funding/financial support

PREVIOUS PRESENTATION IN CONFERENCES: $40^{\text {th }}$ ISPPD National Conference on $24^{\text {th }}$ October 2018 in Nagpur, India

\section{REFERENCES}

1. Vishwakarma AP, Bondarde PA, Patil SB, Dodamani AS, Vishwakarma PY, Mujawar SA. Effectiveness of two different behavioral modification techniques among 57-year-old children: A randomized controlled trial. J Indian Soc Pedod Prev Dent 2017; 35: 143-9.

2. Shah HA, Nanjunda Swamy KV, Kulkarni S, Choubey S. Evaluation of dental anxiety and hemodynamic changes (Sympatho-Adrenal Response) during various dental procedures using smartphone applications $\mathrm{v} / \mathrm{s}$ traditional behaviour management techniques in pediatric patients. Int J Appl Res 2017; 3: 429-33.

3. Kawia HM, Mbawalla HS, Kahabuka FK. Application of behavior management techniques for paediatric dental patients by Tanzanian dental practitioners. Open Dent J 
2015; 9: 455-61.

4. Wright GZ, Stigers JI. Non-pharmacologic management of children's behaviors. In: Dentistry for the Child and Adolescent. 9th ed. Edited by Dean JA, Avery DR, McDonald RE. St. Louis, CV Mosby Co. 2011, p 30.

5. Townsend JA. Behaviour guidance of the paediatric dental patient. In: Paediatric Dentistry- Infancy through Adolescence. 5th ed. Edited by Casa Massimo PS, Fields HW, Mc'Tigue DJ, Nowak AJ. Philadelphia, Elsevier Saunders. 2013, p 358.

6. Frankl SN, Shire FR, Fogels HR. Should the parent remain with the child in the dental operatory? J Dent Child 1962; 29: $150-62$.

7. Buchanan $H$, Niven N. Validation of a Facial Image Scale to assess child dental anxiety. Int J Paediatr Dent 2002; 12: 47-52.

8. Merkel SI, Voepel-Lewis T, Shayevitz JR, Malviya S. The FLACC: a behavioral scale for scoring postoperative pain in young children. Pediatr Nurs 1997; 23: 293-7.

9. Rank RC, Rank MS, Vilela JE, Ogawa WN, Correa MS. Dental anxiety and behavior in young children undergoing different distraction techniques. Pesq Bras Odontoped Clin Integr 2017; 17: 1-11.

10. Abanto J, Vidigal EA, Carvalho TS, Bönecker M. Factors for determining dental anxiety in preschool children with severe dental caries. Braz Oral Res 2017; 31: e13.

11. Melwani AM, Srinivasan I, Setty JV, Pamnani SS, Lalitya D. A clinical comparative study between conventional and camouflaged syringes to evaluate behavior and anxiety in 6-11-year-old children during local anesthesia administration- a novel approach. J Dent Anesth Pain Med 2018; 18: $35-40$.

12. Geetha Priya PR, Asokan S, John JB, Punithavathy R, Karthick K. Comparison of behavioral response to caries removal methods: A randomised controlled cross over trial. J Indian Soc Pedod Prev Dent 2014; 32: 48-52.

13. Mitrakul K, Asvanund Y, Arunakul M, Paka-Akekaphat S. Effect of audiovisual eyeglasses during dental treatment in 5-8 year-old children. Eur Arch Paediatr Dent 2015; 16: 239-45.

14. Bagattoni S, D'alessandro G, Sadotti A, Alkhamis N,
Piana G. Effects of audiovisual distraction in children with special healthcare needs during dental restorations: a randomized crossover clinical trial. Int J Paediatr Dent 2018; 28: 111-20.

15. Riba H. A review of behavior evaluation scales in pediatric dentistry and suggested modification to the Frankl scale. EC Dental Science 2017; 16: 269-75.

16. Patil VH, Vaid K, Gokhale NS, Shah P, Mundada M, Hugar SM. Evaluation of effectiveness of dental apps in management of child behaviour: A pilot study. Int J Pedod Rehabil 2017; 2: 14-8.

17. Wogelius P, Poulsen S, Toft Sørensen H. Prevalence of dental anxiety and behavior management problems among six to eight years old Danish children. Acta Odontol Scand 2003; 61: 178-83.

18. Hoist A, Crossner CG, Hoist A. Direct ratings of acceptance of dental treatment in Swedish children. Community Dent Oral Epidemiol 1987; 15: 258-63.

19. Corkey B, Freeman R. Predictors of dental anxiety in six-year old children: findings from a pilot study. ASDC J Dent Child 1994; 61: 267-71.

20. Cuthbert MI, Melamed BG. A screening device: children at risk for dental fears and management problems. ASDC J Dent Child 1982; 49: 432-6.

21. Adair SM, Waller JL, Schafer TE, Rockman RA. A survey of members of the American Academy of Pediatric Dentistry on their use of behavior management techniques. Pediatr Dent 2004; 26: 159-66.

22. Sharath A, Rekka P, Muthu MS, Rathna Prabhu V, Sivakumar N. Children's behavior pattern and behavior management techniques used in a structured postgraduate dental program. J Indian Soc Pedod Prev Dent 2009; 27: $22-6$.

23. Grewal N. Implementation of behavior management techniques: how well accepted they are today. J Indian Soc Pedod Prev Dent 2003; 21: 70-4.

24. Meshki R, Alidadi F, Behboudi A, Oliadarani FK. Effects of pre-treatment exposure to dental practice using a smartphone dental simulation game on children's pain and anxiety: a preliminary double-blind randomized clinical trial. J Dent 2018; 15: 250-8. 
25. Lee JH, Jung HK, Lee GG, Kim HY, Park SG, Woo SC. Effect of behavioral intervention using smartphone application for preoperative anxiety in pediatric patients. Korean J Anesthesiol 2013; 65: 508-18. 